\title{
Analysis of phospholipids in membrane of Acidithiobacillus ferrooxidans grown in liquid (ferrous sulphate and sodium thiosulphate) and solid (sulfur) substrate
}

\author{
Nathiya $\mathrm{T}^{1}$, Janani R.P $\mathrm{P}^{2}$, Subhaharshni $\mathrm{R}^{3}$, Niranjana Kamala Priya $\mathrm{S}^{4}$ and
} Anand Prem Rajan ${ }^{5 *}$

1,2,3,4,5 Agricultural and Environmental Biotechnology Laboratory, School of Bio Sciences and Technology, VIT University, Vellore- 632014, India.

${ }^{5}$ Research Officer, CO2 and Green Technology, VIT University, Vellore- 632014, India.

\begin{abstract}
Phospholipids (PLs) are the important components of cell membrane of all living organisms. The PL or the cell membrane of the bacteria are the least studied subject as it involves large quantities of material and few methods to assay. The novel study was designed to understand if the cell membrane remains same or it changes during different conditions. The bacteria, Acidithiobacillus ferrooxidans which can live as a planktonic as well as sessile form was chosen to study the difference in Phospholipids present in the cell membrane. The Acidithiobacillus ferrooxidans was grown in liquid substrate Sodium Thiosulphate and a solid substrate Sulfur keeping Ferrous Sulphate substrate grown bacteria as a control. The PLs were extracted using Bligh and Dyer method and concentrated by nitrogen stream drying and isolated using Thin Layer Chromatography (TLC). The isolated PLs were subjected to gas chromatography-mass spectrometry (GC-MS) to characterize the isolated PLs. The results show that $R f$ value of the PLs and the yield were different in Acidithiobacillus ferrooxidans grown in Ferrous Sulphate, Sodium Thiosulphate and Sulfur substrates. The present study has successfully demonstrated for the first time that the PLs were not same in both liquid and solid substrate grown bacteria. Hence it is proved beyond doubt that when bacteria are exposed to different environments they modify the cell membranes to adapt to the new conditions. The Biofilm forming planktonic Acidithiobacillus ferrooxidans bacteria had different PLs profile then sessile bacterial.
\end{abstract}

Keywords: Acidithiobacillus ferrooxidans, Phospholipids, TLC, GC-MS

\section{INTRODUCTION}

Phospholipids (PL) are important constituents of all living cell membranes. The most important mechanism for all living cells including bacterial cell membrane, is the formation of bilayer membrane composed of phospholipids [1]. These bilayer membranes provide shape for the cell and its organelles. It also helps cell to maintain its physiochemical properties, creating an environment inside a cell that is necessary for proteins to interact and function [2]. Therefore even a minute change in membrane phospholipids can lead to drastic change in the membrane causing major defect in cell functions and viability.

Phospholipids act as primary building blocks of every living organism as it acts as an emulsifier, wetting agent and shows a unique self-assembly properties [3]. The emulsifying property of PLs is helpful in maintaining the homeostasis in a cell [4]. Among the various types of bacterial species, the gram negative bacteria holds variety of PLs namely phosphatidyl mono-methylethanolamine, phosphatidyl glycerol, Phosphatidyl dimethylethanolamine, Phosphatidyl ethanolamine, cardiolipin, phosphatidyl choline etc., [5]. PLs has their significant role in cell membrane permeability, fluidity and composition of bacteria. Analysis of phospholipid research was done in many gram positive and gram negative bacteria, to identify new drug compound, under different stress condition, modifying bacterial membrane, etc. In sight in PL change can shed light on various mechanisms like Biofilm formation, bioleaching properties of bacteria.

Acidithiobacillus ferrooxidans is a Gram negative and chemolithoautotrophic rod shaped bacteria. $A$. ferrooxidans can leach the metal by both direct and indirect mechanisms, i.e. attached form (sessile form) and unattached (planktonic form). They use many different electron donors to support their growth and their primary abitat consists of acidic conditions producing a strong reducing environment [6]. They play a major role in bioleaching [7]. They thrive in the acidic conditions with an optimal $\mathrm{pH}$ ranging from $1.5-2.5$ [8]. The major substrate for their growth is iron or sulphur compounds i.e. it oxidizes ferrous sulfate (Fe II) to ferric ions (Fe III) [9] or various reduced sulfur compounds [10]. It can also use hydrogen or formate in oxygenic conditions 
[11]. Further, under anoxygenic conditions $A$. ferrooxidans reduces the ferric (Fe III) to ferrous ions (Fe II) [12] or can use hydrogen as electron donors $[13,14]$. In presence of oxygen-sufficient conditions (OSC), $A$. ferrooxidans oxidizes sodium thiosulfate to tetrathionate, which accumulates in the culture medium. Tetrathionate is then oxidized by a tetrathionate hydrolase (TTH) enzyme which generates thiosulfate, elemental sulfur, and sulfate as final products.

A. ferrooxidans were analyzed for many membrane studies like surface protein induced for the adhesion on mineral particles [15], but not for Phospholipids. The present study was designed to examine if there was any change in phospholipids composition in the cell membrane of A. ferrooxidans when it was grown in liquid (ferrous sulphate and sodium thiosulphate) substrate and solid (sulfur) substrates.

\section{EXPERIMENT}

\subsection{Sample Collection and acclimatization}

For present study pure culture of A. ferrooxidans was provided by Department of Materials Engineering, Indian Institute of Science, Bangalore. Bacteria were grown in $9 \mathrm{~K}$ culture media containing basal salts (ammonium sulfate $-3 \mathrm{~g} / \mathrm{L}$, dipotassium phosphate $-0.5 \mathrm{~g} / \mathrm{L}$, magnesium sulfate $-0.5 \mathrm{~g} / \mathrm{L}$, potassium chloride $-0.1 \mathrm{~g} / \mathrm{L}$, calcium nitrate $-0.01 \mathrm{~g} / \mathrm{L}$ and ferrous sulphate - 44.7) of $\mathrm{pH} 2.3$. The culture was incubated in temperature control orbital shaker (Orbitek - LE, Refrigerated Orbital Shaker Scigenic Make) at $30^{\circ} \mathrm{C}$ and maintained at 260 $\mathrm{rpm}$. For every 15 days, subculture was done to maintain pure culture [15]. The experiment was started after 30 days of acclimatization to the laboratory conditions.

\subsection{Media preparation for liquid (Sodium Thiosulphate) and solid (Sulfur) substrate}

The $A$. ferrooxidans were inoculated in two different substrates namely sodium thiosulphate and sulfur. The components of $9 \mathrm{~K}$ media containing basal salts remained same in both the cases. $30 \mathrm{~g}$ of fine powdered sulphur along with $10 \mathrm{mg}$ of ferrous sulfate was added to make solid substrate in 1 Litre deionized water and the $\mathrm{pH}$ was maintained at 2 using Sulphuric Acid.

$10 \mathrm{~g}$ of sodium thiosulfate and $10 \mathrm{mg}$ of ferrous sulfate was added in 1 Litre of deionized water to provide liquid substrate. The $\mathrm{pH}$ was maintained at 4.5 using Sulphuric Acid.

The Erlenmeyer flasks were incubated at $30^{\circ} \mathrm{C}$ at $260 \mathrm{rpm}$. PLs were extracted from two different substrates keeping the Ferrous Sulfate media i.e 9K media as control.

The A. ferrooxidans, inoculum used in used in substrate was prepared by filtering through $0.22 \mu \mathrm{m}$ Millipore membrane. The bacterial pellet was washed twice with $20 \mathrm{~mL} \mathrm{pH} 2$ sulfuric acid solutions to remove iron followed by distilled water wash to remove residual acid. The cell count of these exponential phase bacteria were $5 \times 10$ power 6 cells per ml. The resuspended bacterial were aseptically transferred to the Erlenmeyer flasks containing solid and liquid substrates. The sample were collected for the phospholipids extraction after 10 days of inoculation. All the experiments were done in triplicate and repeated twice to minimize experimental and handling errors.

\subsection{Extraction of Phospholipids}

The phospholipids were extracted using Bligh and Dyer method [16] with slight modifications. The bacterial culture was filtered to remove precipitates. The supernatant containing bacteria was centrifuged at $10,000 \mathrm{rpm}$ for $10 \mathrm{~min}$. The supernatant was discarded and the cells were washed with deionized water. The cells were suspended in $6 \mathrm{ml}$, solvent mixture of methanol: dichloromethane: sodium phosphate buffer in the ratio of 2:1:0.8 was added [17]. In this study, chloroform was avoided due to its toxicity. The above sample mixture was ultrasonicated for $10 \mathrm{~min}$ to break cells membranes and release of PLs in the biphasic separation. This mixture was kept at room temperature for overnight. To this mixture methanol: dichloromethane: water in the ratio of 1:1:0.9 was added and again ultrasonicated for 5 minutes. The mixture was centrifuged at 10,000 rpm for 10 min resulting in separation of two phases. The lower phase containing PLs were reduced in volume by drying in nitrogen stream. The dried samples were dissolved in methanol and used for further studies.

\subsection{Thin Layer Chromatography analysis}

In order to detect the presence of PLs, the thin layer chromatography was performed. The precoated silica sheets were used as stationary phase [21]. The solvent system varying in ratios and polarity were used as a mobile phase. DCM: methanol: acetic acid: water in the ratio 25:15:4:2 was used as mobile phase. The samples 
extracted from control, liquid and solid substrates were analyzed by TLC for the presence of PLs. A dot of the sample was loaded in TLC sheet. Based on their composition and affinity, PLs migrate on stationary phase. The spots were visualized by bromothymol blue. The ratio of distance moved by the analyte from origin to the distance moved by the flowing solvent from the origin is known as retention factor (Rf value) that is used for the identification of components. The resulted spots were eluted and were subjected to the GC-MS analysis.

\subsection{GC-MS analysis}

For analysis, GC-MS (GC model Clarus 680 and mass spectrometer Clarus 600 (EI); Perkin Elmer, Inc., America) was used to identify different compounds in the test samples. It was equipped with a split/splitless injector and FID. Separation of FAME (Fatty Acid Methly Esters) was carried out on a fused silica capillary column (Elite-5MS, $30.0 \mathrm{~m}, 0.25 \mathrm{~mm}$ ID, $250 \mu \mathrm{m}$ film thickness), coated with a very polar bis-cyanopropyl stationary phase. Helium was used as a carrier gas. The flow rate of sample was $1 \mathrm{ml} / \mathrm{min}$. The amount injected was $1 \mu \mathrm{l}$ and the split ratio was $10: 1$. The temperature of the injector was $250^{\circ} \mathrm{C}$. The oven temperature was held at $60^{\circ} \mathrm{C}$ for $1 \mathrm{~min}$, and then, programmed the ramp $10^{\circ} \mathrm{C} / \mathrm{min}$ to $300^{\circ} \mathrm{C}$, and hold there for $6 \mathrm{~min}$. Finally, the total run took 32 minutes. In mass condition (EI), solvent delay at $2 \mathrm{~min}$, transfer temperature set as $240^{\circ} \mathrm{C}$ and source temperature as $240^{\circ} \mathrm{C}$. The injected sample was scanned from 50 to $600 \mathrm{Da}$.

\section{Results And Discussion}

The PLs were extracted from different substrates were weighed after drying with nitrogen stream using modified Bligh and Dyer method (Bligh and Dyer, 1959). The extracted phospholipids from different substrate grown bacteria are shown in Figure 1.

Figure 1 The phospholipids extracted from Acidithiobacillus ferrooxidans grown in a) Ferrous Sulphate b) Sodium Thiosulphate and c) Sulfur substrate can be seen as non-soluble floating globule in the picture.

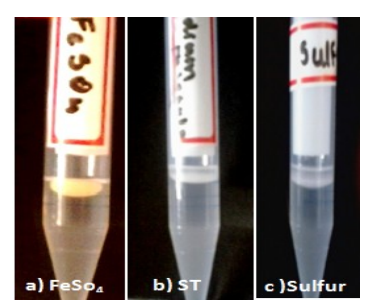

The yield of PLs was calculated using the following equation:

Yield $(Y)$ per $500 \mathrm{ml}$ of culture media = Weight of the falcon tube containing dried sample (W2) - Weight of the empty tube (W1).

The phospholipids yield from Acidithiobacillus ferrooxidans grown in ferrous sulphate, sodium thiosulphate and sulfur substrates is given in Table 1.

The order of phospholipid obtained from $500 \mathrm{ml}$ of Acidithiobacillus ferrooxidans grown in different substrates are

$$
\text { Ferrous Sulphate }>\text { Sodium Thiosulphate }>\text { Sulfur }
$$

The higher yield in ferrous sulphate was $0.3 \mathrm{~g}$ followed by sodium thiosulfate $0.2 \mathrm{~g}$ indicates that liquid substrates resulted in more phospholipids compared to solid substrates like sulphur.

Table 1 shows the yield of Phospholipids obtained from Acidithiobacillus ferrooxidans grown in ferrous sulphate, sodium thiosulphate and sulfur substrates.

\section{TLC analysis}

\begin{tabular}{lc}
\hline Substrate & Yield $(\mathrm{g} / 500 \mathrm{ml})$ \\
\hline Ferrous sulphate & $0.3 \mathrm{~g}$ \\
Sodium thiosulfate & $0.2 \mathrm{~g}$ \\
Sulfur & $0.1 \mathrm{~g}$ \\
\hline
\end{tabular}

The dried PL samples were loaded on TLC sheets to confirm the presence of PLs. The TLC sheets were placed in mobile phase containing DCM: methanol: acetic acid: water. The results showed the spots in both liquid (ferrous sulphate and sodium thiosulphate) and solid (sulfur) substrates grown Acidithiobacillus ferrooxidans. The retention factors were calculated and given in Table 2.

The retention factor (Rf) value for PL obtained from Acidithiobacillus ferrooxidans grown in different substrates were found to be different i.e. 0.5, 0.385 and 0.328. The results of Rf value show that the Phospholipids isolated from same bacteria Acidithiobacillus ferrooxidans grown in different substrates produced different phospholipids instead of same type. 
Table 2 shows the Rf value of Phospholipids obtained from Acidithiobacillus ferrooxidans grown in ferrous sulphate, sodium thiosulphate and sulfur substrates performed by Thin Layer Chromatorgraphy.

\begin{tabular}{c|c|c}
\hline S.No & Substrate & RF value \\
\hline 1 & Ferrous sulphate & 0.5 \\
2 & Sodium thiosulphate & 0.385 \\
3 & Sulphur & 0.328 \\
\hline
\end{tabular}

GC-MS analysis

Phospholipids from Acidithiobacillus ferrooxidans grown in Ferrous Sulphate

The GC-MS analysis of phospholipids isolated from ferrous sulphate grown Acidithiobacillus ferrooxidans indicated the presence of following compounds 3-methyl-2-(2-oxopropyl)furan, phenol, 3,5-bis(1,1-dimethylethyl)-, dodecanoic acid 3-dodecanoyloxy-propyl ester, 2,6,10,14,18,22-tetracosahexaene,

2,6,10,15,19,23-hexamethyl-, (all-e)-, 1,2benzenedicarboxylic acid, mono(2-ethylhexyl) ester, chloroacetic acid, tetradecyl ester chloroacetic acid, tetradecyl ester dodecane and 1-fluoro-hexacosanol acetate (Figure 2)

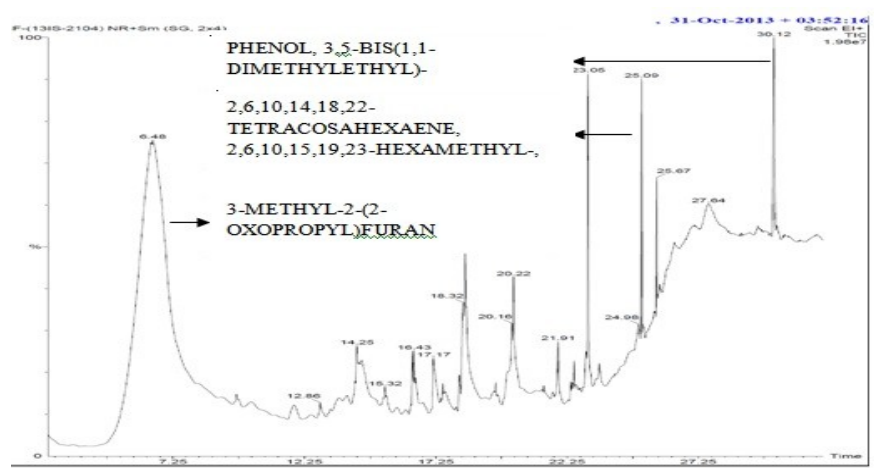

Figure 2 shows the GC MS profile of the Phospholipids analysis of $A$. ferrooxidans grown in ferrous sulphate substrate

\section{Phospholipids from Acidithiobacillus ferrooxidans grown in Sodium thiosulfate}

The sodium thiosulfate sample was subjected to GC-MS analysis and the obtained peaks were correlated with the given standard peaks. The compounds were predicted as 2-tert-butyl-3,4,5,6tetrahydropyridine,

2-isothiocyano-2,4,4,6,6pentamethylheptane, silanamine, $\quad \mathrm{n}, 1,1,1-$ tetramethyl-n-[1-methyl-2-phenyl-2-[(trimethylsilyl

oleic acid, didodecyl phthalate, 1,2benzenedicarboxylic acid, mono(2-ethylhexyl) ester (Figure 3).

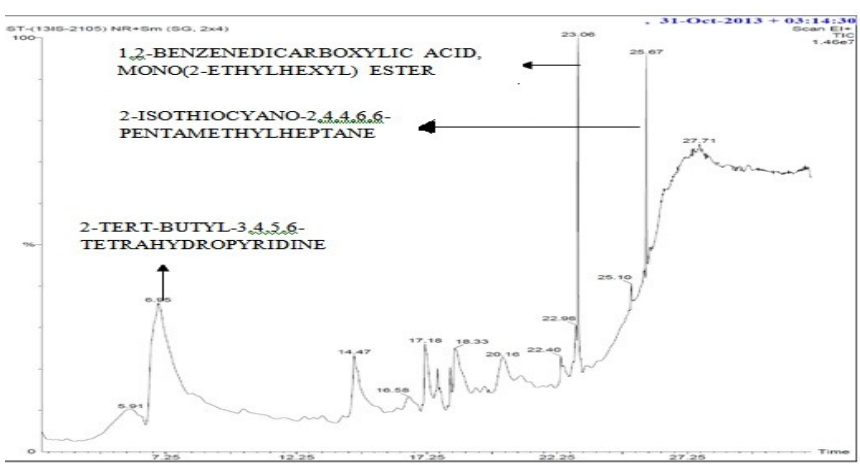

Figure 3 shows the GC MS profile of the Phospholipids analysis of A. ferrooxidans grown in Sodium thiosulfate substrate

Phospholipids from Acidithiobacillus ferrooxidans grown in Sulfur

The compounds from GC-MS analysis in the sulphur sample were predicted to be 3 butoxy1,1,1,5,5,5-hexamethyl-

3(trimethylsiloxy)trisiloxane, phenol,3,5bis(1,1 imethylethyl)-,chloroacetic acid, tetradecyl ester phenol,4,4'-(1-methylethylidene) bis-, which were determined by comparing with the library search (Figure 4).

Figure 4 shows the GC MS profile of the

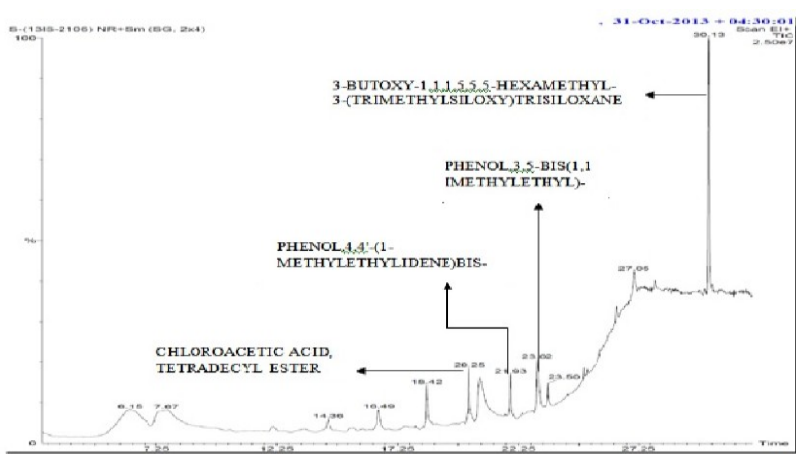
Phospholipids analysis of $A$. ferrooxidans grown in Sulfur substrat 


\section{Conclusion}

The present study has successfully demonstrated for the first time that the membrane phospholipids were not same in both liquid and solid substrate grown bacteria. Hence it is proved beyond doubt that when bacteria are exposed to different environments they modify the cell membranes to adapt to the new conditions. The Biofilm forming planktonic Acidithiobacillus ferrooxidans bacteria had different PLs profile then sessile bacterial. Biofilm formation by Acidithiobacillus ferrooxidans may be regulated by new PLs present in the cell membrane. The industrial processes, Biofilm formation, biofouling and attachment related mechanisms may be accelerated or decelerated by targeting specific PLs.

\section{Acknowledgements}

Authors want to thank and acknowledge the funding and support for the project "Differential membrane lipid profile and fluidity of Acidithiobacillus ferrooxidans during the process of adhesion to minerals" under SERB Scheme, DST- with the reference of DO No. SR/S3/ME/0025/2010. The study may not be successfully completed without the support of Prof. K. A. Natarajan, NASI Senior Scientist Platinum Jubilee Fellow, Department of Materials Engineering, Indian Institute of Science, Bangalore, India. Authors wants to thank Dr. Preston Devasia, Singapore for his constant input and guidance during the work as well as during manuscript preparation. We also thank Mr. H. Madhesan Sophisticated Instrument Facility Laboratory for GC MS analysis.

\section{References}

[1] B. L. Peterson and B. S. Cummings A review of chromatographic methods for the assessment of phospholipids in biological samples, Biomedical Chromatography, 20, 2006, 227-243.

[2[ E. Camera, M. Picardo, C. Presutti, P. Catarcini and S. Fanali, Separation and characterization of sphingoceramides by high-performance liquid chromatography-electrospray ionization mass spectrometry, Journal of Separation Science, 27(12), 2004, 971-976

[3] K.M. Parris, Phospholipids: Versatile Nutraceuticals for functional foods, Functional foods and nutraceuticals, 2002, 111

[4] P.B. Joshua, and C.O.Rock, Bacterial lipids: Metabolism and membrane homeostasis, Progress in lipid research, 52, 2013, 249-276.

[5] S.A. Steven, W.C. David, and M.I.H. Aleem, Phospholipid Metabolism in Ferrobacillus ferrooxidans, Journal of Bacteriology, 99, 1969, 142-150.

[6] A. Sato, F. Fukumori, T. Yano, and T.Yamanaka, Fe (II)-oxidizing enzyme purified from Thiobacillus ferrooxidans, FEMS Microbiology Letters, 1989, 169-172.

[7] O. Tuovinen, H.Tuhela, and L.Carlson, (1993). Biogeochemical transformations of Fe and Mn in oxic groundwater and well water environments, Journal of Environmental Science Health, 32, 1993, 407-426.

[8] D.E. Rawlings, I.M. Pretorius, and D.R. Woods, Expression of Thiobacillus ferrooxidans plasmid functions and the development of genetic systems for the Thiobacilli, Biotechnol. Bioengineering. Symposium, 16, 1986, 281-287

[9] W.A., Karrie, A.A. Laurie, and C.D. John, Microorganisms pumping iron: anaerobic microbial iron oxidation and reduction, Nature Reviews, Microbiology Department of plant and Microbial biology, 4, 2006, $752-764$

[10] L.G. Leduc, and G.D. Ferroni, The chemolithotrophic bacterium Thiobacillus ferrooxidans, FEMS Microbiology Letters, 108, 1994, 103-120.

[11] E. Drobner, H. Huber, and K. Stetter, Thiobacillas ferrooxidans, a facultative hydrogen oxidizer, Applied and environmental microbiology, 56, 1990, 2922-2923.

[12] D.R. Lovley, Genesis, Evolution and Diversity of Life. Journal. Seckbach, 2004, 707.

[13] A. Das, A.K Mishra, and P .Roy, Anaerobic growth on elemental sulfur using dissimilar iron reduction by autotrophic Thiobacillus ferrooxidans, FEMS Microbiol Letters, 1992, 97.

[14] N. Ohmura, K. Sasaki, N. Matsumoto, and H. Saiki, Anaerobic respiration using $\mathrm{Fe}^{3+}, \mathrm{S}^{0}$, and $\mathrm{H}_{2}$ in the chemolithoautotrophic bacterium Acidithiobacillus ferrooxidans. Journal of Bacteriology, 184, 2002, 2081-2087.

[15] P. Devasia, K.A. Natarajan, and G.R. Rao, Role of bacterial growth conditions and adhesion in the bioleaching of chalcopyrite by Thiobacillus ferrooxidans, Minerals and Metallurgical Processing, 1996, 95-643.

[16] E.G. Bligh, and W.J. Dyer, A rapid methodfor total lipid extraction and purification, Canadian .Journal of .Biochemistry and.Physiology, 37, 1959, 911-917.

[17] M. M. Yakimov, P.N. Golyshin, S. Lang, R. B. Edward. Moore, Wolf-Rainer Abraham, Heinrich and K.N. Timmis, (1998) Alcanivorax borkurnensis gen. now, sp. nov.,a new, hydrocarbon-degrading and surfactant-producing marine bacterium. International Journal of Systematic Bacteriology, 4, 1998, 339-348.

[18] F. Parker, and N.F. Peterson, Quantitative Analysis of Phospholipids and Phospholipid Fatty Acids from Silica Gel ThinLayer Chromatograms, Journal of Lipid Research 6, 1965, 455-460. 